\title{
Spatial distribution of Schistosoma mansoni infection before and after chemotherapy with two praziquantel doses in a community of Pernambuco, Brazil
}

\author{
Aline F Galvão', Tereza C Favre', Ricardo JPS Guimarães ${ }^{2,3}$, Ana PB Pereira', \\ Luciana C Zani', Katariny T Felipe ${ }^{1}$, Ana Lúcia C Domingues ${ }^{4}$, Omar S Carvalho², \\ Constança S Barbosa ${ }^{5}$, Otávio S Pieri ${ }^{1 /+}$
}

\begin{abstract}
'Laboratório de Ecoepidemiologia e Controle da Esquistossomose e Geohelmintoses, Instituto Oswaldo Cruz-Fiocruz, Av. Brasil 4365, 21040-360 Rio de Janeiro, RJ, Brasil 'Laboratório de Helmintoses e Malacologia Médica, Instituto de Pesquisas René Rachou-Fiocruz, Belo Horizonte, MG, Brasil ³Programa de Pós-Graduação, Santa Casa de Misericórdia de Belo Horizonte, Belo Horizonte, MG, Brasil ${ }^{4}$ Departamento de Medicina Clínica, Centro de Ciências da Saúde, Universidade Federal de Pernambuco, Recife, PE, Brasil ${ }^{5}$ Departamento de Parasitologia, Instituto Aggeu Magalhães-Fiocruz, Recife, PE, Brasil
\end{abstract}

Praziquantel chemotherapy has been the focus of the Schistosomiasis Control Program in Brazil for the past two decades. Nevertheless, information on the impact of selective chemotherapy against Schistosoma mansoni infection under the conditions confronted by the health teams in endemic municipalities remains scarce. This paper compares the spatial pattern of infection before and after treatment with either a $40 \mathrm{mg} / \mathrm{kg}$ or $60 \mathrm{mg} / \mathrm{kg}$ dose of praziquantel by determining the intensity of spatial cluster among patients at 180 and 360 days after treatment. The spatial-temporal distribution of egg-positive patients was analysed in a Geographic Information System using the kernel smoothing technique. While all patients became egg-negative after 21 days, $17.9 \%$ and $30.9 \%$ reverted to an egg-positive condition after 180 and 360 days, respectively. Both the prevalence and intensity of infection after treatment were significantly lower in the $60 \mathrm{mg} / \mathrm{kg}$ than in the $40 \mathrm{mg} / \mathrm{kg}$ treatment group. The higher intensity of the kernel in the $40 \mathrm{mg} / \mathrm{kg}$ group compared to the $60 \mathrm{mg} / \mathrm{kg}$ group, at both 180 and 360 days, reflects the higher number of reverted cases in the lower dose group. Auxiliary, preventive measures to control transmission should be integrated with chemotherapy to achieve a more enduring impact.

Key words: schistosomiasis - praziquantel - geographical information systems - spatial clustering - epidemiology

Schistosomiasis mansoni remains a serious public health problem in Brazil, as it is estimated to affect 6-7 million people primarily in the North-East Region (Coura \& Amaral 2004). Since the decentralization of the Schistosomiasis Control Program (PCE) within the Unified Health System (SUS) in the 1990s, surveillance and control actions have been carried out at the municipal level under the supervision of the states in accordance with the guidelines established by the Ministry of Health (MS) (Amaral et al. 2006). At present, the MS recommends an active search of infected persons through periodic stool surveys of whole communities. The MS also recommends treatment of the infected individuals with $50-60 \mathrm{mg} / \mathrm{kg}$ of praziquantel (PZQ) to prevent an increase in morbidity and to establish auxiliary control measures such as health education and environment sanitation to reduce transmission (MS 2007). According

Financial support:UNICEF/UNDP/WorldBank/WHO/TDR(A20764), NIH-Fogarty (5D43TW007012)

+ Corresponding author: opieri@ioc.fiocruz.br

Received 12 February 2009

Accepted 13 November 2009 to the Computerized System of the PCE (MS 2008), out of a total of 13,652,085 stool examinations performed between January 2001-October 2008 in the country, $852,473(6.2 \%)$ were positive for Schistosoma mansoni eggs. Of the positive cases, 77,630 (9.1\%) were from the endemic area of the state of Pernambuco (PE). In this area, 2,499 localities were surveyed by the PCE within the SUS (PCE-SUS) over that period while 1,252 (50.1\%) had a proportion of positive examinations above 5\%. According to recent guidelines by the MS (MS 2007), prevalence above $5 \%$ requires special attention of the health teams that supervise schistosomiasis surveillance and control in the area.

Few municipalities have executed sustained actions of surveillance and control under the PCE-SUS due to material and human limitations (Favre et al. 2006a, b). In fact, of the 3.4 million people inhabiting the endemic area of that state, only $828,365(24 \%)$ were examined until now (MS 2008). Therefore, there is a dearth of information on the present status of the infection and the impact of PZQ treatment under the conditions faced by the PCE-SUS in that highly endemic area.

The Geographical Information System (GIS) is a powerful tool that could be used to understand disease transmission better because schistosomiasis is determined by spatial and temporal risk factors. GIS can be used to identify environmental features which allows the determination of risk factors and delimitation of risk areas, lead- 
ing to the optimization of resources and the improvement of actions against the specific conditions of the disease (Bergquist 2002, Guimarães et al. 2006, 2008).

Schistosomiasis tends to cluster within communities due to the focality of risk factors and transmission (Gazzinelli et al. 2006). Studies on disease clustering involve the identification of areas with a higher temporal or spatial (or both) risk of disease, or the assessment of elevated risk around presumed sources of hazard (Bailey 2001). Cluster analysis of the spatial distribution of $S$. mansoni infection in Brazil that was aimed at identifying highrisk areas was used by Gazzinelli et al. (2006) in Virgem das Graças, Minas Gerais and by Araújo et al. (2007) in Porto de Galinhas, PE to verify the correlation between snail foci and human cases. In China, Zhang et al. (2009) also used cluster analysis to identify high-risk regions for Schistosoma japonicum infection. In Kenya, Clennon et al. (2004) identified significant clustering of high infection by Schistosoma haematobium among children. Despite these reports, little is known about the effects of chemotherapy on the spatial distribution of the disease.

Clinical studies to determine the best PZQ treatment regimen on the different schistosoma species for different regions were performed on hospital patients (Chen et al. 1985, da Cunha et al. 1987) and under field conditions encountered by the health teams of the control programs (King et al. 1989, Abu-Elyazeed et al. 1997, Guisse et al. 1997, Beck et al. 2001, Tchuenté at al. 2004). Only recently have multi-country clinical trials been conducted under the same core protocol in different endemic areas to compare the efficacy of $60 \mathrm{mg} / \mathrm{kg}$ single dose of PZQ with the standard dose of $40 \mathrm{mg} / \mathrm{kg}$ recommended by the World Health Organization (WHO) (WHO 2006), which has low effectiveness in certain areas.

The data published here have resulted from a series of trials coordinated by the WHO Special Program for Research and Training in Tropical Diseases (TDR), which is aimed at optimizing the use of PZQ. The trials compared the efficacy and safety of the most common single dosages $(40 \mathrm{mg} / \mathrm{kg}$ and $60 \mathrm{mg} / \mathrm{kg})$ used in the treatment of schistosomiasis. The work done with S. japonicum in the Philippines (Belizario et al. 2008) showed that the two dose regimens resulted in comparable egg-negative rates (ENR) $(95 \%$ and $98 \%$, respectively) after 21 days. However, the proportion of subjects who reverted to the eggpositive condition one year post-treatment was significantly higher in the $40 \mathrm{mg} / \mathrm{kg}$ dose than in the $60 \mathrm{mg} / \mathrm{kg}$ (62.5\% and $48.5 \%$, respectively). As the $40 \mathrm{mg} / \mathrm{kg}$ dose was shown to be better tolerated than the higher dose, the authors recommended the lower dose for the treatment of schistosomiasis japonica in that country.

The objective of this study was to compare the spatial pattern of the infection before and after treatment with two different PZQ doses (40 and $60 \mathrm{mg} / \mathrm{kg}$ ) in an area endemic for schistosomiasis mansoni and to determine the magnitude of spatial clustering among patients to examine changes in the prevalence of infection at 180 and 360 days after drug administration. The data on safety/tolerability of the two treatment regimens will be discussed in a future publication.

\section{PATIENTS, MATERIALS AND METHODS}

Study area - The locality chosen for the present study (Nova Tiúma) belongs to the municipality of São Lourenço da Mata, which is located in the sugar-cane zone of PE at a distance of $16.3 \mathrm{~km}$ from the state capital, Recife. The climate of the area is tropical, primarily hot and humid. The average temperature is $25^{\circ} \mathrm{C}$ and the yearly cumulative rainfall is $2,000 \mathrm{~mm}$, with a marked rainy season from April-July. There exist fresh-water marshland plants in the vicinity of watercourses and on humid lowlands, as well as on the remains of the original rainforest on the hilly areas. However, these vegetation patterns have been extensively altered by sugar-cane plantation. The main watercourses are the rivers Capibaribe and two of its perennial tributaries, Tapacurá and Goitá (FIDEM 2003). The area is also plentifully endowed with small water collections such as streams, marshes and pools, particularly in the rainy season (Pieri \& Thomas 1987).

The municipality encompasses an area of $264.35 \mathrm{~km}^{2}$ with an estimated population of 95,304 (IBGE 2009). The population is primarily urban; however, the economic activities are predominantly rural, such as subsistence and cash-crop agriculture, cattle ranching and aviculture. The region has a history of relatively high prevalence of persisting $S$. mansoni infection despite successive cycles of population surveys and treatment campaigns carried out by the MS from 1977-1995, which was prior to the decentralization of PCE (Pieri et al. 1995, 1998, Moza et al. 1998, Beck et al. 2001, Favre et al. 2001). A total of 69 localities were covered in that period, varying from 26 in 1977 to 62 in 1995. An average of 10,270 residents was examined per cycle and the prevalence rates were: $34.8 \%$ (1977), 18\% (1979), 16.2\% (1982), 29.8\% (1986) and $24.7 \%$ (1995). After the PCE was decentralized within the SUS, only 17 localities were covered from 2005-2007, where a total of 23,177 residents were examined and 1,536 (6.6\%) were egg-positive.

A sketch map of Nova Tiúma is shown in Fig. 1. According to the Information System on Primary Health Care, in 2006 Nova Tiúma had 760 families distributed in 54 blocks of houses, with a total population of 2,975 residents (1,418 males and 1,557 females). The age-group distribution was: 484 ( $<10$ years), 629 (10-19 years), 1,121 (20-39 years) and 741 ( $>39$ years). Piped water and garbage collection by the municipal department of public works reached $78 \%$ and $79 \%$ of the households respectively. However, only $39 \%$ of the households had access to the public sewage disposal system; the remainder made use of pits (51\%) and open-air sewage ditches (10\%).

The main water course of Nova Tiúma is the Capibaribe River, which runs southwards on the western limit of the locality. The river is used by the population primarily for leisure, household tasks, fishing, fording and washing animals. Two seasonally drying streams flow across the locality into the Capibaribe River. One runs on the southeastern boundary of the locality and is heavily polluted by industrial waste from a nearby slaughterhouse; the other flows along the streets retaining water in isolated pools and ditches even during the dry season. Other potential breeding places for the inter- 


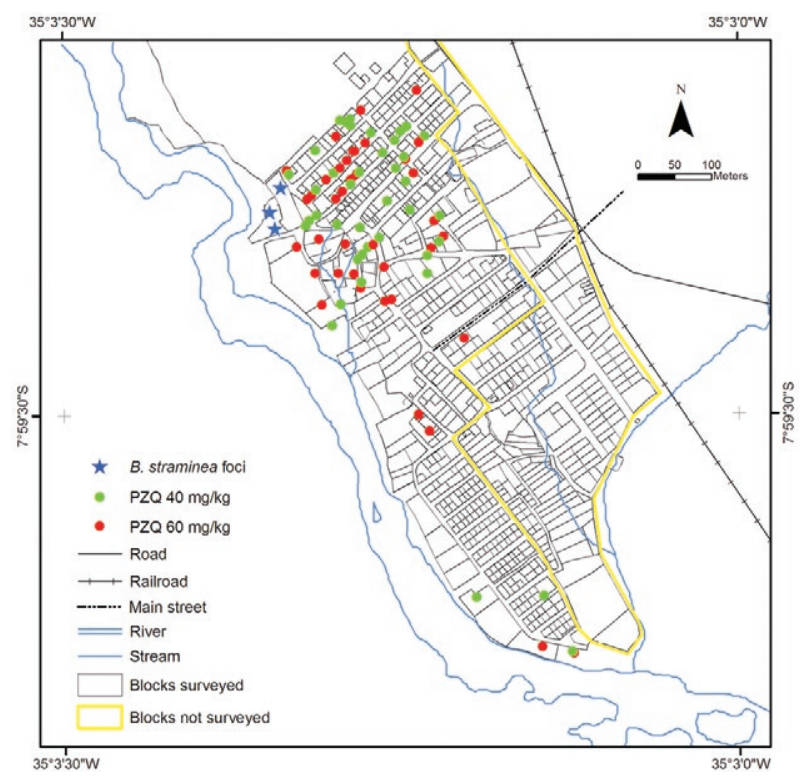

Fig. 1: sketch map of Nova Tiúma showing the spatial distribution of the patients treated with either $40 \mathrm{mg} / \mathrm{kg}$ (green circles) or $60 \mathrm{mg} / \mathrm{kg}$ (red circles) single dose of praziquantel (PZQ). The Biomphalaria straminea foci are indicated by stars. The blocks inside the yellow contour were not surveyed.

mediate host snails were provided by small backwaters, springs and constant runoff from taps and latrines.

A malacological survey conducted in the vicinity of Nova Tiúma identified through the polymerase chain reaction the presence of Biomphalaria straminea infected by S. mansoni, confirming the occurrence of active transmission of the disease in the study area (Melo et al. 2006).

Subjects - A preliminary parasitological survey among adolescents (10-19 years) was conducted by the Fiocruz Schistosomiasis Reference Service of Aggeu Magalhães Research Center (CPqAM-Fiocruz) in August 2006 that covered 34 of the 54 blocks. The locality was divided into two sets of 27 blocks: one southeast and the other northwest of the main street (Fig. 1). Due to operational difficulties, the survey covered only 12 of the southeastern blocks and 22 of the northwestern ones. A total of 547 adolescents were registered, of which 422 $(77.2 \%)$ lived northwest of the main street. Of the total registered, 454 were examined by the Kato-Katz method (Katz et al. 1972) and 204 (45\%) had eggs of S. mansoni in the faeces (1 sample, 2 slides). Of the egg-positive adolescents, $29(14.2 \%)$ lived in the southeast and 175 $(85.8 \%)$ resided in the northwest of the locality.

All adolescents identified as egg-positives for S. mansoni in the preliminary survey were invited to participate in the study. They were interviewed at their homes regarding the fulfilment of the following inclusion criteria: 1019 years of age and written informed consent agreeing to participate in the screening phase of the trial. The participants received stool vials and were asked to provide stool samples (2 samples within a 5-day interval) that were collected at their homes the following days and examined by the Kato-Katz method (2 slides for each sample). Only those who had at least 100 eggs per gram of faeces (epg) in the screening phase were enrolled for treatment and follow-up. The interval between screening and treatment was shorter than seven days. The exclusion criteria, as evaluated by a physician, were pregnancy or lactation, acute or chronic severe diseases, use of PZQ in the last 30 days, known hypersensitivity associated with PZQ, current use of other medication that could affect the results of the trial such as antibiotics and corticosteroids and any medical condition that hampered subject participation.

Treatment and follow-up - Enrolled subjects were randomly assigned to one of the following treatment groups: Group A (single oral dose of PZQ $40 \mathrm{mg} / \mathrm{kg}$ ) or Group B (single oral dose of PZQ $60 \mathrm{mg} / \mathrm{kg}$ ). The randomization was generated in blocks of four at a rate of 1:1 for each group. TDR provided the PZQ $600 \mathrm{mg}$ tablets (Shin Poong Pharmaceutical Co Ltd, Korea) as well as the sealed and numbered envelopes containing the treatment regimen for each sequential patient. Two stool samples ( 2 slides each) collected within five-day intervals were examined by the Kato-Katz method at 21 \pm 2 days, $180 \pm 7$ days and $360 \pm 14$ days after treatment. Participants who for any reason were excluded from the study and had positive $S$. mansoni diagnosis received standard schistosomiasis treatment (MS 2007) with PZQ provided by the Institute of Drug Technology (Farmanguinhos/Fiocruz). Subjects identified as positive for other helminths (Ascaris lumbricoides, Trichuris trichiura and hookworms) were treated with mebendazole 600 $\mathrm{mg}$ (100 mg twice daily for 3 days) in the visits at 21 and 360 days. Mebendazole was provided by the Aeronautics Chemical and Pharmaceutical Laboratory.

Parasitological assessment and analysis - The status of $S$. mansoni infection from each subject was assessed by counting the eggs of the Kato-Katz slides. The epg of faeces for each time point was determined as the average count of the four slides prepared for each individual multiplied by 24 . Subjects were considered egg-negative if the egg count of the four slides was zero. The proportion of egg-positive participants was presented as percentage of the total examined. The intensity of infection was given by the geometric mean egg count (GMEC), which was calculated from $\log _{10}(\mathrm{epg}+1)$ transformed values so that the logarithm of zero egg count (for negative result) could be computed.

The impact of treatment on the prevalence of infection was assessed by determining the ENR as the proportion of participants who became negative 21 days after treatment. The impact of treatment on the intensity of infection was assessed by calculating the egg reduction rate (ERR) for each subject by the formula: [1 - (epg2/epg1)] x 100, where epg1 and epg2 were the epg of faeces at the screening survey and at the 21st day post-treatment survey. Eggpositive rates (EPR) were determined as the proportion of participants who were egg-negative after treatment (21 or 180 days) and reverted to egg-positive at a subsequent examination (180 or 360 days). 
Parasitological data were entered in an Excel spreadsheet (Microsoft Office 2007, Microsoft Corporation, Redmond, WA, USA) and transferred to the Systat 11 (Systat Software, Inc, Richmond, CA, USA) statistical package for analysis. The impact of treatment on the prevalence of infection was evaluated by comparing the ENR at 21 days between the groups using contingency tables (Chi-square test or Fisher exact test). Contingency tables were also used to evaluate significant differences at the 0.05 level ( 2 tailed) in EPR between the treatment groups both at 180 and 360 days.

The impact of treatment on intensity of infection was analysed by comparing the GMEC between the groups using repeated measures analysis of variance (ANOVA) to identify significant differences at baseline and at 21 days. ANOVA for repeated measures was also used to identify significant differences in the GMEC as regards dose regimen, assessment time (180 and 360 days) and the interaction effect between assessment time and dose.

Malacological assessment - The water-bodies of the study area were identified and potential transmission foci were demarcated as collecting stations for monthly surveying of the local intermediate host snails, $B$. straminea. This allowed the detection of active transmission foci and the estimation of focal infection rates as described by Favre et al. (2002). Snails were individually screened at weekly intervals over one month for cercarial shedding and then crushed to verify the presence of early larval stages of S. mansoni.

Spatial analysis - A digitalised map was acquired from the Municipal Development Foundation (FIDEM
2003) for creation of the Nova Tiúma cartographic base. This included blocks of houses, streets, lots and water collections. The geographical coordinates of the residential address of each patient and of the B. straminea foci were captured using a hand-held Global Positioning System receiver (12XL Personal Navigator, GARMIN Corporation, Kansas, USA) and recorded in a Universal Transverse Mercator coordinate system (SAD 69 datum). Spatial data were stored and analysed in a GIS, ArcGis 9.3 software (Environmental Systems Research Institute, Redlands, CA, USA) for manipulation and linking the descriptive attributes to the graphical shape, as well as visualisation, spatial analysis and update of the data in the system.

The spatial-temporal distribution of the study subjects prior to and after treatment was analysed through the kernel smoothing technique, a nonparametric method used to estimate the amount of events per area unit in each cell of a regular grid covering the area (Bailey $\&$ Gatrell 1995). Clusters of egg-positive patients were generated by this technique and defined as a geographically bound group of close values unlikely to have occurred at random (Mitchell 2005). A bandwidth of $50 \mathrm{~m}$ was used for estimating kernel density of egg-positive patients. The results were depicted as thematic maps.

Ethics - This research protocol follows the Guidelines and Regulations for Research Involving Human Beings (resolution 196/1996 of the National Health Council) and complies with the principles of the Declaration of Helsinki 1975 as revised in 1983. It was approved by the Research Ethical Committee of CPqAM-Fiocruz, CAEE:

TABLE

Number and percentage of Schistosoma mansoni egg-positive patients and geometric mean of individual egg counts (GMEC) per gram of faeces (epg) using $\log _{10}(\mathrm{epg}+1)$ transformation at baseline (screening survey) and at 21, 180 and 360 days after treatment with either $40 \mathrm{mg} / \mathrm{kg}$ (Group A) or $60 \mathrm{mg} / \mathrm{kg}$ (Group B) of praziquantel

\begin{tabular}{|c|c|c|c|c|}
\hline Assessments & Infection & $\begin{array}{c}\text { Group A } \\
\mathrm{n}=64\end{array}$ & $\begin{array}{c}\text { Group B } \\
\mathrm{n}=59\end{array}$ & $\begin{array}{c}\text { Total } \\
\mathrm{n}=123\end{array}$ \\
\hline & Number of egg-positive & 64 & 59 & 123 \\
\hline & $\%$ & 100 & 100 & 100 \\
\hline \multirow[t]{3}{*}{ Baseline } & GMEC & 322.8 & 348.3 & 335 \\
\hline & Number of egg-positive & 0 & 0 & 0 \\
\hline & $\%$ & 0 & 0 & 0 \\
\hline \multirow[t]{3}{*}{ Day 21} & GMEC & 0 & 0 & 0 \\
\hline & Number of egg-positive & 17 & 5 & 22 \\
\hline & $\%$ & 26.6 & 8.5 & 17.9 \\
\hline \multirow[t]{3}{*}{ Day 180} & GMEC & 2.1 & 1.3 & 1.7 \\
\hline & Number of egg-positive & 26 & 12 & 38 \\
\hline & $\%$ & 40.6 & 20.3 & 30.9 \\
\hline Day 360 & GMEC & 3.9 & 2.4 & 3.1 \\
\hline
\end{tabular}

n: number of patients followed up to day 360 . 
0736.0.095.000-05 and by the WHO Secretariat Committee on Research Involving Human Subjects (SCRIHS) on 18 February 2004. Collection, transportation and maintenance of the schistosomiasis intermediate host snail were licensed (11297-1) from the Brazilian Institute of Environment and Renewable Natural Resources.

\section{RESULTS}

One hundred and thirty-eight subjects were enrolled and 69 were randomly assigned for each treatment group. Within the study population, 71 were females and 67 were males. Fourteen subjects in the study ( 3 females, 11 males) were lost to follow-up and one was excluded because the geographical coordinates of his residential address were not recorded. Therefore, 123 patients were considered for the study, with 64 in the $40 \mathrm{mg} / \mathrm{kg}$ treatment group (Group A) and 59 in the $60 \mathrm{mg} / \mathrm{kg}$ treatment group (Group B). Fig. 1 depicts the cartographic base of Nova Tiúma including housing, streets and potential habitats for the host snails and the spatial distribution of the study patients. All 123 subjects had the geographical coordinates of their residential address registered to a total of 79 households, varying from 1-4 individuals per household. Ten households were southeast and 69 were northwest of the main street. The 64 subjects treated with $40 \mathrm{mg} / \mathrm{kg}$ PZQ occupied 52 households; five resided southeast and 47 lived northwest of the main street. The 59 subjects of the $60 \mathrm{mg} / \mathrm{kg}$ treatment group occupied 50 households; five were southeast and 45 were northwest of the main street (Fig. 1).

The Table shows the parasitological data before and after treatment. At baseline (screening survey) there was no significant difference in the GMEC between Group
A and $B(A=322.8$ epg, $B=348.3$ epg, $p=0.594)$. At 21 days after treatment all subjects became negative for infection by $S$. mansoni. As a result, both the ENR and the ERR were $100 \%$ regardless of the dose regimen. The proportion of positives in group A was significantly higher than in group $\mathrm{B}$ both at 180 days $(\mathrm{A}=26.6 \%$, $\mathrm{B}=8.5 \%, \mathrm{p}=0.009)$ and at 360 days $(\mathrm{A}=40.6 \%$, $\mathrm{B}=20.3 \%, \mathrm{p}=0.015)$ (Table).

Of the 123 subjects, 46 reverted to egg-positive at a subsequent examination, 32 (69.6\%) belonged in Group A and 14 (30.4\%) in Group B. Therefore, the EPR was significantly higher $(\mathrm{p}=0.003)$ at the $40 \mathrm{mg} / \mathrm{kg}$ dose regimen than among those who received the $60 \mathrm{mg} / \mathrm{kg}$ dose. In addition, 22 (47.8\%) of the 46 reverted cases were detected at 180 days after treatment, with 17 belonging in Group A and five in Group B. The remaining 24 (52.2\%) were detected at 360 days, with 15 in Group A and nine in Group B. It is interesting to note that the proportion of subjects who were egg-positive at 180 and remained so at 360 days was statistically similar $(\mathrm{p}=0.848)$ for the two doses (11 in 17 for Group A and 3 in 5 for Group B).

Post-treatment GMEC was significantly higher in Group A $(40 \mathrm{mg} / \mathrm{kg})$ than in Group B $(60 \mathrm{mg} / \mathrm{kg})$ both at $180(\mathrm{~A}=2.1 \mathrm{epg}, \mathrm{B}=1.3 \mathrm{epg})$ and 360 days after treatment $(\mathrm{A}=3.9 \mathrm{epg}, \mathrm{B}=2.4 \mathrm{epg})$. Repeated measures ANOVA detected significant differences both in dose $(p=0.026)$ and assessment time $(p=0.000)$. There was no significant interaction effect between assessment time and dose $(\mathrm{p}=0.892)$.

Seven collecting stations of $B$. straminea were demarcated and georeferenced, four along the Capibaribe River left margins and three in a peridomiciliary area at the northwestern corner of the locality. This area served
A

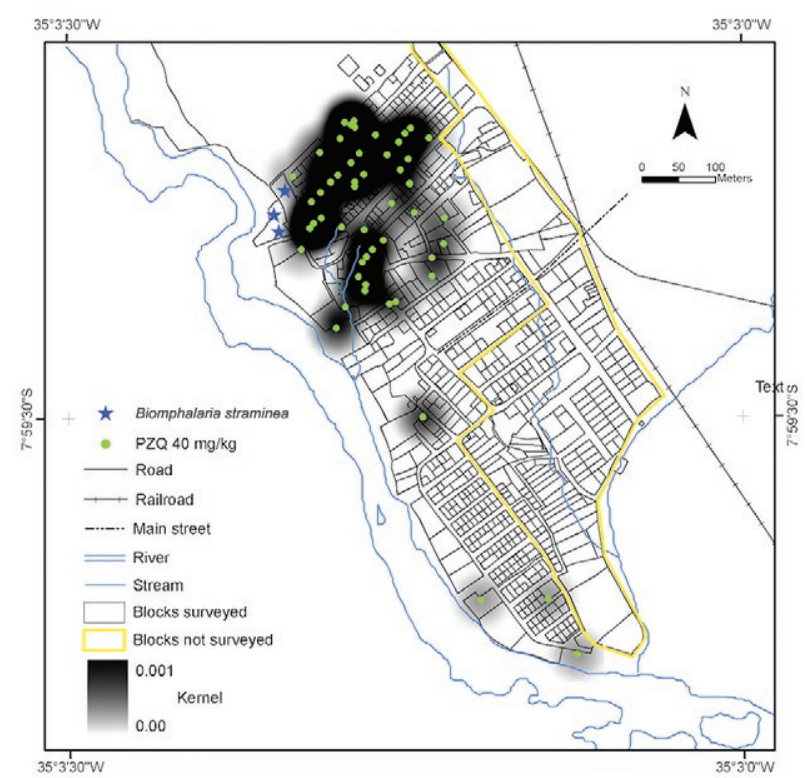

B

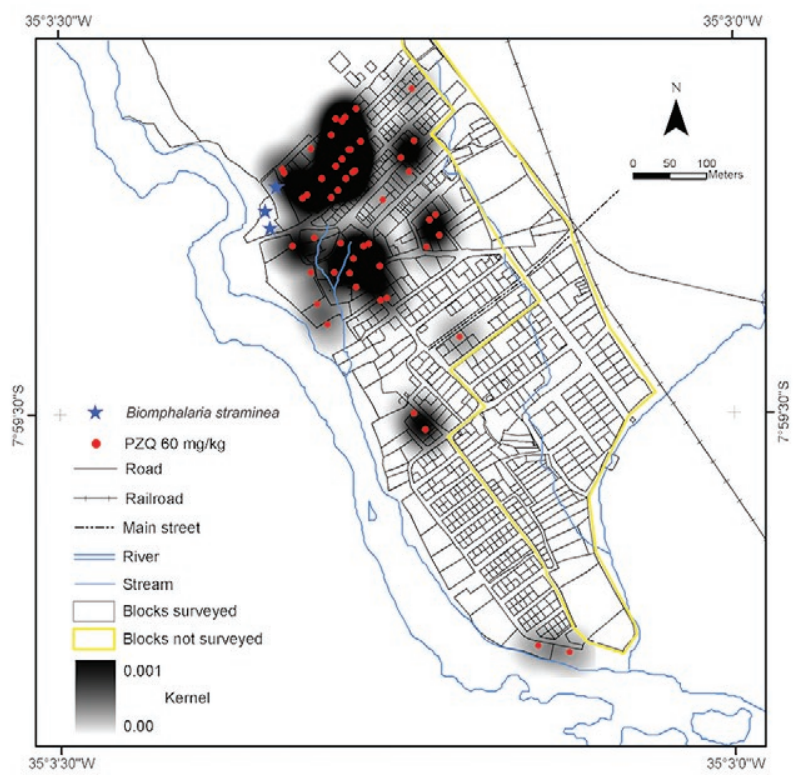

Fig. 2: kernel density estimates for egg-positive patients at baseline (screening survey), prior to treatment with either praziquantel (PZQ) $40 \mathrm{mg} /$ $\mathrm{kg}(\mathrm{A})$ or PZQ $60 \mathrm{mg} / \mathrm{kg}(\mathrm{B})$. 
A

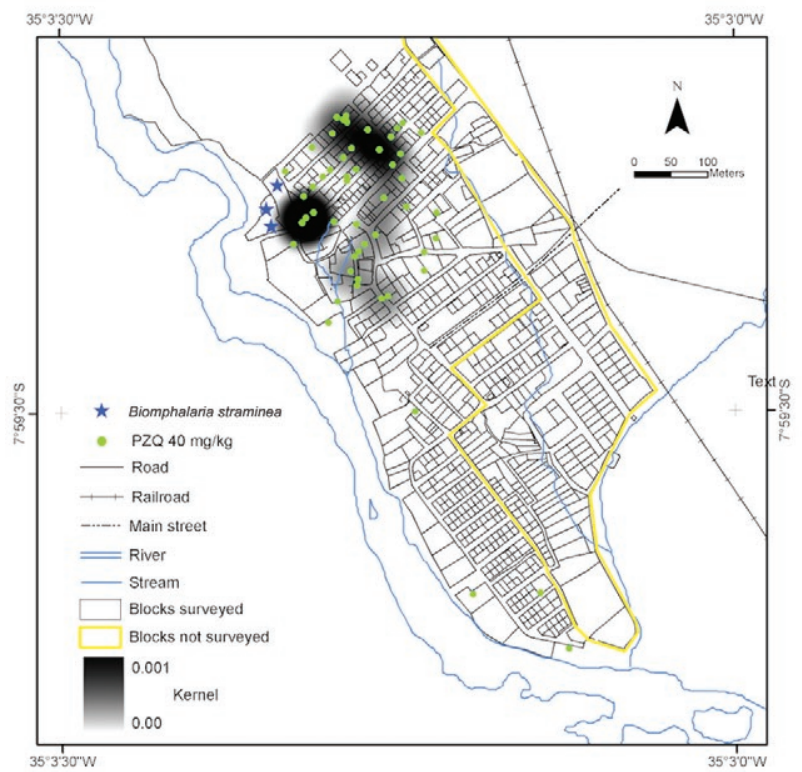

B

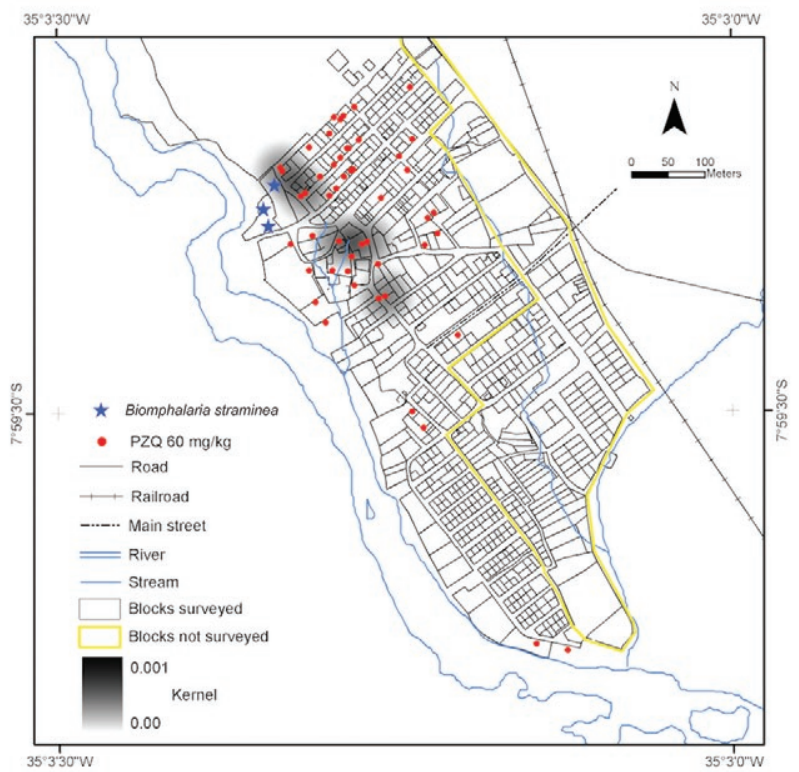

Fig. 3: kernel density estimates for egg-positive patients at 180 days after treatment with either praziquantel (PZQ) $40 \mathrm{mg} / \mathrm{kg}$ (A) or PZQ $60 \mathrm{mg} / \mathrm{kg}$ (B).

as a pathway for the local population to assess the river and provided an opportunity of constant water contact, particularly during the rainy season. No snails were found in the Capibaribe River stations over the follow-up period. However, a total of 3,149 snails were collected from the three peridomiciliary stations, all of which harboured snails that had been infected with $S$. mansoni at least once between 180-360 days of follow-up resulting in a collection of 15 specimens: eight with cercarial shedding and seven with early larval stages (Fig. 1). The monthly focal infection rates of $B$. straminea ranged from $0-2.2 \%$.

Fig. 2 shows clusters of the study subjects prior the treatment with either PZQ $40 \mathrm{mg} / \mathrm{kg}$ (A) or PZQ $60 \mathrm{mg} /$ $\mathrm{kg}$ (B). The highest density of cases was concentrated northwest of the main street, as most of the enrolled subjects lived in that area. Comparison of the spatial distribution between groups A and B showed that their kernel density was visually similar regarding shading intensity and extension. The analysis of the spatial distribution 21 days after treatment was not accomplished because all patients were egg-negative.

Figs 3 and 4 depict the clusters of those patients who were egg-positive at 180 and 360 days respectively. Comparison of the spatial distribution of patients who reverted to the egg-positive condition at 180 days showed that clusters of the $40 \mathrm{mg} / \mathrm{kg}$ group had a higher intensity than the $60 \mathrm{mg} / \mathrm{kg}$ group. A similar pattern was also observed at 360 days.

\section{DISCUSSION}

The parasitological results indicate that both $40 \mathrm{mg} /$ $\mathrm{kg}$ and $60 \mathrm{mg} / \mathrm{kg}$ PZQ single dose therapy had an exceedingly high and comparable impact on infection at 21 days after treatment. However, subjects given the higher dose
$(60 \mathrm{mg} / \mathrm{kg})$ were able to maintain significantly lower levels of both prevalence and intensity of infection up to one year after treatment than those given the standard dose (40 $\mathrm{mg} / \mathrm{kg}$ ). Assuming that the absence of eggs at six months or longer after treatment constitutes a reliable criterion for parasitological cure (Ferrari et al. 2003), the significantly higher proportion of egg-negative subjects found in the $60 \mathrm{mg} / \mathrm{kg}$ group up to 360 days after treatment indicates that the higher dose regimen has a higher therapeutic efficacy. As pointed out by da Cunha \& Pedrosa (1986), the drug may temporally suppress oviposition by females as the worms migrate from the mesenteric veins to the liver. If the worms are not killed, they may return to the mesenteric veins and resume egg-laying up to three months after PZQ treatment. If this does not occur, subjects who subsequently revert to the egg-positive condition may be regarded as cases of re-infection and not recrudescence. In the present paper, 24 of the 46 reverted cases were indeed re-infections, as they were detected only at 360 days after treatment. However, the 22 reverted cases that were detected at 180 days could neither be confirmed to be reinfection nor recrudescence as all patients remained at risk of infection during the follow-up period. Thus, further work is necessary to distinguish between re-infection and recrudescence under such conditions.

The patterns of the spatial distribution by dose regimen and assessment time is depicted in Figs 2-4 and reflect changes in the parasitological status of the subjects in the trial (Table). At baseline, the observed similar distribution was not unexpected as patients were randomly allocated to either group. The higher intensity of the kernel in the $40 \mathrm{mg} / \mathrm{kg}$ group than in the $60 \mathrm{mg} / \mathrm{kg}$ group, both at 180 and 360 days, reflects the higher number of reverted cases found in the lower dose group along the trial. 
A

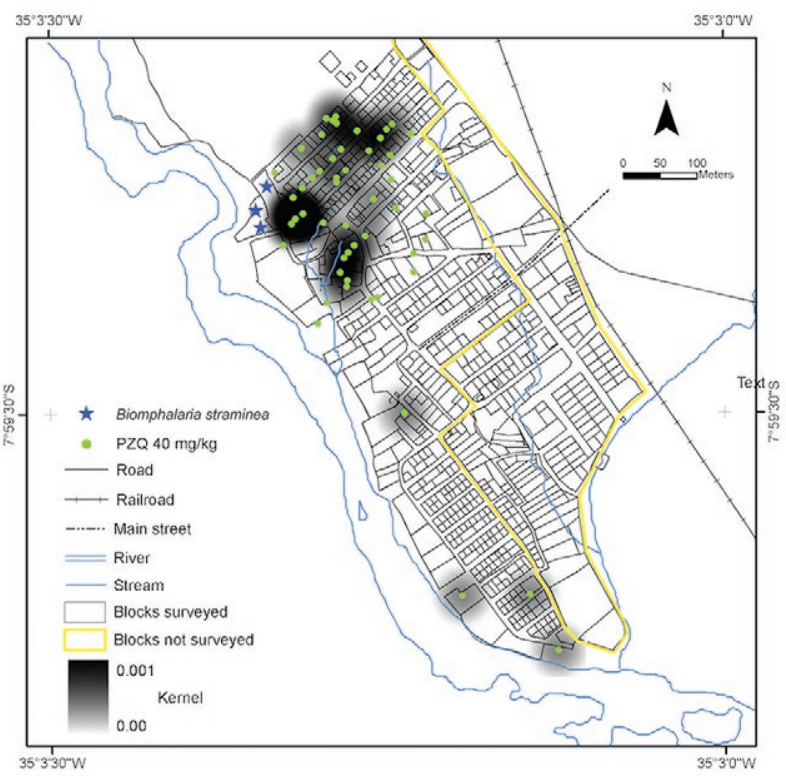

B

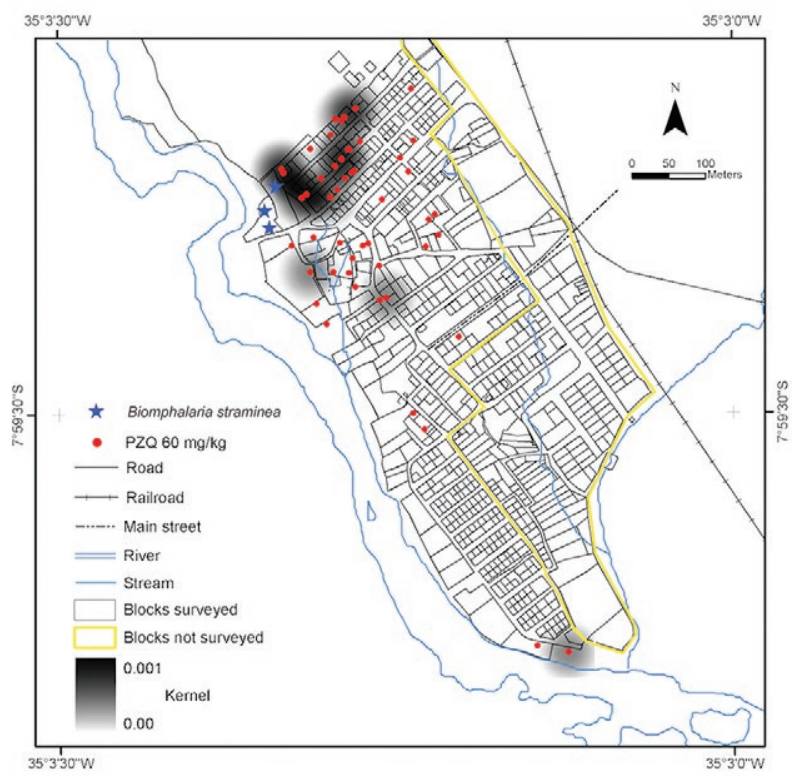

Fig. 4: kernel density estimates for egg-positive patients at 360 days after treatment with either praziquantel (PZQ) $40 \mathrm{mg} / \mathrm{kg}$ (A) or PZQ $60 \mathrm{mg} / \mathrm{kg}$ (B).

It is interesting to note that the increasing intensity of the clustering patterns of egg-positive subjects in both treatment groups among baseline 180 and 360 days posttreatment may be ascribed to the maintenance of favourable conditions for transmission after treatment, as shown by the detection of naturally infected snails in the same collecting stations over the follow-up period.

The present results support the use of the higher $(60 \mathrm{mg} /$ $\mathrm{kg}$ ) PZQ dose for the treatment of schistosomiasis mansoni in the endemic areas of Northeast Brazil not only because of its higher therapeutic efficacy, but also for its longer lasting impact on the spatial distribution of the reverted cases following treatment. However, it is also clear from this study that drug treatment alone is unable to interrupt transmission due to recrudescence/re-infection. Considering that untreated cases also contribute to the maintenance of transmission in such high-risk areas, preventive measures such as health education, environmental sanitation, safe water supply and snail control should be combined with chemotherapy to achieve a more enduring impact (King 2009).

\section{ACKNOWLEDGEMENTS}

To the staff of the Fiocruz Schistosomiasis Reference Service of Aggeu Magalhães Research Center, for the technical support throughout the study, specially to Sebastião Alves dos Santos, for his valuable field work, to the community leader Edileuza Felix da Luz and the people of Nova Tiúma, for their cooperation, to the State Secretary of Health of Pernambuco and the São Lourenço da Mata Municipal Secretary of Health, for providing information from the Information System on Primary Health Care, to the Laboratory of National Reference in Medical Malacology-Fiocruz, for the identification of the larval stages of Schistosoma mansoni, and to Dr. Ubiraci Guida (in memoriam), from The National Health Foundation, for providing the parasitological data from the municipality of São Lourenço da Mata in the period 1977-1995.

\section{REFERENCES}

Abu-Elyazeed RR, Youssef FG, Merrell BR, El-Gamal RL, El-Khoby TA, Hassanein YA, Cummings CE 1997. Praziquantel in the treatment of Schistosoma mansoni infection: comparison of 40 and 60 mg/kg bodyweight regimens. Am J Trop Med Hyg 56: 404-407.

Amaral RS, Tauil PL, Lima DD, Engels D 2006. An analysis of the impact of the Schistosomiasis Control Programme in Brazil. Mem Inst Oswaldo Cruz 101 (Suppl. I): 79-85.

Araújo KCGM, Resendes APC, Souza-Santos R, Silveira-Júnior JC, Barbosa CS 2007. Análise espacial dos focos de Biomphalaria glabrata e de casos humanos de esquistossomose mansônica em Porto de Galinhas, Pernambuco, Brasil, no ano 2000. Cad Saude Publica 23: 409-417.

Bailey TC 2001. Spatial statistical methods in health. Cad Saude Publica 17: 1083-1098.

Bailey TC, Gatrell AC 1995. Interactive spatial data analysis, Longman, Harlow, 413 pp.

Beck L, Favre TC, Pieri OS, Zani LC, Domas GG, Barbosa CS 2001. Replacing oxamniquine by praziquantel against Schistosoma mansoni infection in a rural community from the sugar-cane zone of Northeast Brazil: an epidemiological follow-up. Mem Inst Oswaldo Cruz 96: 165-167.

Belizario Jr VY, Amarillo MLE, Martinez RM, Mallari AO, Tai CMC 2008. Efficacy and safety of $40 \mathrm{mg} / \mathrm{kg}$ and $60 \mathrm{mg} / \mathrm{kg}$ single doses of praziquantel in the treatment of schistosomiasis. Pediatr Infect Dis J 3: 27-34.

Bergquist NR 2002. Schistosomiasis: from risk assessment to control. Trends Parasitol 18: 309-314.

Chen MG, Hua XJ, Wang MJ, Xu RJ, Yu CB, Jiang SB 1985. Dose finding double-blind clinical trial with praziquantel in schistosomiasis japonica patients. Southeast Asian J Trop Med Public Health 16: 228-233.

Clennon JA, King CH, Muchiri EM, Kariuki HC, Ouma JH, Mungai $\mathrm{P}$, Kitron U 2004. Spatial patterns of urinary schistosomiasis in- 
fection in a highly endemic area of coastal Kenya. Am J Trop Med Hyg 70: 443-448.

Coura JR, Amaral RS 2004. Epidemiological and control aspects of schistosomiasis in Brazilian endemic areas. Mem Inst Oswaldo Cruz 99 (Suppl. I): 13-19.

da Cunha AS, Cançado JR, de Rezende GL 1987. Therapeutical evaluation of different dose regimens of praziquantel in schistosomiasis mansoni, based on the quantitative oogram technique. Rev Inst Med Trop Sao Paulo 29: 295-304.

da Cunha AS, Pedrosa RC 1986. Double-blind therapeutical evaluation based on the quantitative oogram technique, comparing praziquantel and oxamniquine in human schistosomiasis mansoni. Rev Inst Med Trop Sao Paulo 28: 337-351.

Favre TC, Pieri OS, Barbosa CS, Beck L 2001. Evaluation of control measures implemented from 1977 to 1996 in the endemic area of schistosomiasis in Pernambuco, Brazil. Rev Soc Bras Med Trop 34: 569-576.

Favre TC, Pieri OS, Zani LC, Ferreira JM, Domás GG, Beck LH, Barbosa CS 2002. A longitudinal study on the natural infection of Biomphalaria straminea and B. glabrata by Schistosoma manso$n i$ in an endemic area of schistosomiasis in Pernambuco, Brazil. Mem Inst Oswaldo Cruz 97: 465-475.

Favre TC, Ximenes RAA, Galvão AF, Pereira APB, Wanderley TN, Barbosa CS, Pieri OS 2006a. Attaining the minimum target of resolution WHA 54.19 for schistosomiasis control in the Rainforest Zone of the state of Pernambuco, Northeastern Brazil. Mem Inst Oswaldo Cruz 101 (Suppl. I): 125-132.

Favre TC, Ximenes RAA, Galvão AF, Pereira APB, Wanderley TN, Barbosa CS, Pieri OS 2006b. Reliability of current estimates of schistosomiasis prevalence in the Rainforest Zone of the state of Pernambuco, Northeastern Brazil. Mem Inst Oswaldo Cruz 101 (Suppl. I): 73-78.

Ferrari ML, Coelho PM, Antunes CM, Tavares CA, da Cunha AS 2003. Efficacy of oxamniquine and praziquantel in the treatment of Schistosoma mansoni infection: a controlled trial. Bull World Health Organ 81: 190-196.

FIDEM - Fundação de Desenvolvimento Municipal 2003. Planta diretora do município de São Lourenço da Mata, FIDEM, Recife, $78 \mathrm{pp}$.

Gazzinelli A, Hightower A, LoVerde PT, Haddad JPA, Pereira WR, Bethony J, Correa-Oliveira R, Kloos H 2006. The spatial distribution of Schistosoma mansoni infection before and after chemotherapy in the Jequitinhonha Valley in Brazil. Mem Inst Oswaldo Cruz 101 (Suppl. I): 63-71.

Guimarães RJ, Freitas CC, Dutra LV, Moura AC, Amaral RS, Drummond SC, Scholte RG, Carvalho OS 2008. Schistosomiasis risk estimation in Minas Gerais state, Brazil, using environmental data and GIS techniques. Acta Trop 108: 234-241.

Guimarães RJPS, Freitas CC, Dutra LV, Moura ACM, Amaral RS, Drummond SC, Guerra M, Scholte RGC, Freitas CR, Carvalho OS 2006. Analysis and estimative of schistosomiasis prevalence for the state of Minas Gerais, Brazil, using multiple regression with social and environmental spatial data. Mem Inst Oswaldo Cruz 101 (Suppl. I): 91-96.

Guisse F, Polman K, Stelma FF, Mbaye A, Talla I, Niang M, Deelder AM, Ndir O, Gryseels B 1997. Therapeutic evaluation of two diffe- rent dose regimens of praziquantel in a recent Schistosoma manso$n i$ focus in Northern Senegal. Am J Trop Med Hyg 56: 511-514.

IBGE - Instituto Brasileiro de Geografia e Estatística 2009. IBGE Cidades. [cited 2009 Jan 5]. Available from: http://www.ibge.gov.br/ cidadesat/topwindow.htm?1.

Katz N, Chaves A, Pellegrino J 1972. A simple device for quantitative stool thick-smear technique in schistosomiasis mansoni. Rev Inst Med Trop Sao Paulo 14: 397-400.

King CH 2009. Toward the elimination of schistosomiasis. $N$ Engl J Med 360: 106-109.

King CH, Wiper DW 3rd, De Stigter KV, Peters PA, Koech D, Ouma JH, Arap Siongok TK, Mahmoud AA 1989. Dose-finding study for praziquantel therapy of Schistosoma haematobium in Coast Province, Kenya. Am J Trop Med Hyg 40: 507-513.

Melo FL, Gomes AL, Barbosa CS, Werkhauser RP, Abath FG 2006. Development of molecular approaches for the identification of transmission sites of schistosomiasis. Trans R Soc Trop Med Hyg 100: 1049-1055.

Mitchell A 2005. The ESRI guide to GIS analysis: spatial measurements and statistics, ESRI Press, Redlands, $252 \mathrm{pp}$.

Moza PG, Pieri OS, Barbosa CS, Rey L 1998. Fatores sócio-demográficos e comportamentais relacionados à esquistossomose em uma agrovila da zona canavieira de Pernambuco, Brasil. Cad Saude Publica 14: 107-115.

MS - Ministério da Saúde/Secretaria de Atenção à Saúde/Departamento de Atenção Básica 2007. Vigilância em saúde: dengue, esquistossomose, hanseníase, malária, tracoma e tuberculose, Normas e Manuais Técnicos, Série A, Cadernos de atenção básica 21, MS, Brasília, 199 pp.

MS - Ministério da Saúde/Secretaria de Vigilância em Saúde 2008. Programa de Controle da esquistossomose. Departamento de Informática do Sistema Único de Saúde - DATASUS. [cited 2009 Jan 5]. Available from: http://tabnet.datasus.gov.br/cgi/tabcgi. exe?sinan $/$ pce/cnv/pce.def.

Pieri OS, Barbosa CS, Moza PG 1998. Schistosomiasis control based on repeated chemotherapy in a rural village of the sugar-cane zone in Northeast Brazil. Mem Inst Oswaldo Cruz 93 (Suppl. I): 259-264.

Pieri OS, Gonçalves JF, Sarquis O 1995. Repeated focal mollusciciding for snail control in a sugar-cane area of Northeast Brazil. Mem Inst Oswaldo Cruz 90: 535-536.

Pieri OS, Thomas JD 1987. Snail host control in the eastern coastal areas of Northeast (NE) Brazil. Mem Inst Oswaldo Cruz 82 (Suppl. IV): 197-201.

Tchuenté LA, Shaw DJ, Polla L, Cioli D, Vercruysse J 2004. Efficacy of praziquantel against Schistosoma haematobium infection in children. Am J Trop Med Hyg 71: 778-782.

WHO - World Health Organization/Department of Control of Neglected Tropical Diseases (NTD) 2006. Preventive chemotherapy in human helminthiasis. Coordinated use of anthelmintic drugs in control interventions: a manual for health professionals and programme managers. Preventive chemotherapy and transmission control (PCT), WHO, Geneva, 74 pp.

Zhang Z, Clark AB, Bivand R, Chen Y, Carpenter TE, Peng W, Zhou Y, Zhao G, Jiang Q 2009. Nonparametric spatial analysis to detect high-risk regions for schistosomiasis in Guichi, China. Trans R Soc Trop Med Hyg 103: 1045-1052. 